\title{
Por una nosología de la violencia del narcotráfico: topos literarios de los años de la peste*
}

Fecha de recepción: 01 de octubre de 2014

Fecha de aprobación: 28 de febrero de 2015

\section{Resumen}

En el presente artículo se analiza algunos topos de la violencia del narcotráfico en Colombia en cuatro novelas contemporáneas; haciendo énfasis en las décadas de los ochenta y noventa, contexto histórico recreado por los textos, y que en este trabajo llamaremos "años de la peste”. El objetivo es demostrar, desde un análisis semiológico, que el narcotráfico como sistema de producción es símbolo y síntoma de la ausencia del Estado; por lo que presentamos la relación "morbosa" entre narcotráfico y violencia que se reconstruye narrativamente en el corpus seleccionado, para caracterizar lo que llamaremos narco-violencia y entenderla como una epidemia ${ }^{1}$ que irrumpió históricamente en la cotidianidad colombiana.

Palabras Clave: narco-violencia, epidemia, ausencia de Estado, literatura colombiana, semiología.

*Artículo de reflexión. Este trabajo hace parte del segundo capítulo de la Tesis Doctoral, La construcción narrativa de la violencia en Colombia: 1994-2011, que tiene como objetivo principal indagar en las figurativizaciones y temas de la violencia (entendida como significante) del narcotráfico en La virgen de los sicarios (Vallejo, 1994), Comandante Paraíso (Álvarez Gardeazábal, 2002), Delirio (Restrepo, 2004) y El ruido de las cosas al caer (Vásquez, 2012).

Citar: Solano Cohen, V. (julio - diciembre de Zois). Por nosología de la violencia del narcotráfico: topos literarios de los años de la peste. La Palabra, (27),79-92.

\author{
Vanessa Solano Cohen \\ Universidad Diego Portales \\ vanessa.solano@mail.udp.cl
}

Doctoranda en Estudios Sociales de América Latina, Universidad Nacional de Córdoba, Argentina; Diploma de Estudios Avanzados en Literatura comparada, Instituto de Humanidades, Universitat Pompeu Fabra de Barcelona; Profesional en Estudios Literarios, Pontificia Universidad Javeriana de Bogotá, Colombia. Docente de la Universidad Diego Portales, Santiago de Chile.

1. Retomamos el término epidemia a partir de la conceptualización elaborada por Canghilhem (1971), como una enfermedad que ataca al mismo tiempo y con características inmutables a un gran número de personas. La epidemia por lo tanto, para Canghilhem, es histórica, colectiva y múltiple. 


\section{Towards a nosology of the violence of drug-traffic: literary topos from the years of the plague}

\section{Abstract}

This article is an analysis of some of the topos of the violence of drug traffic in Colombia in four contemporary novels, emphasizing on the eighties and nineties, the historical context recreated by these texts, which in this paper we will call the "plague years". The objective is to demonstrate, based on a semiotic analysis, that drug traffic, as production system, is a symbol and symptom of absence of State. In order to do this, we describe the "morbid" relation between drug traffic and violence, recreated in the selected literary corpus, in order to characterize narco-violence as an epidemic that irrupts historically in Colombian everyday life.

Keywords: narco-violence, epidemic, absence of State, Colombian literature, semiology.

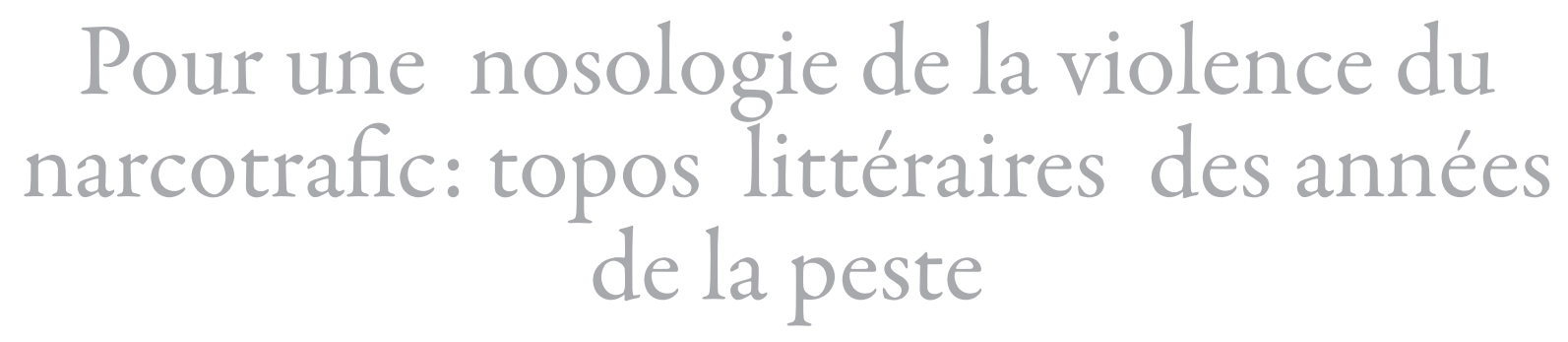

Résumé

Cet article analyse certains topos de la violence liée au narcotrafic en Colombie à travers quatre romans contemporains. Nous privilégierons les années 80 et 90, contexte historique recréé dans les textes, et nous nous y référerons comme « les années de la peste ». Il s'agit de démontrer, depuis une analyse sémiologique, que le narcotrafic en tant que système de production est symbolique et symptomatique de l'absence de l'État. C'est pour cela que nous étudierons le rapport « morbide » entre narcotrafic et violence qui se construit narrativement dans le corpus choisi, pour caractériser ce que nous appellerons narco-violence et la comprendre comme une épidémie ayant fait irruption dans la quotidienneté colombienne.

Mots clés: narco-violence, épidémie, absence de l'État, littérature colombienne, sémiologie. 
La literatura como saber patognóstico

En Las épocas y sus enfermedades. El saber patognóstico, Jochen Hörisch (2006) expone que Hamlet presenta a la melancolía como la gran enfermedad del siglo XVII, época en la que el tiempo y el espacio, según el autor, habían perdido el juicio. El texto de Shakespeare, en el análisis de Hörisch, es el punto de partida para afirmar que la literatura es un discurso social que tiende "a la tematización de enfermedades/épocas (Hörisch, 2006, p.52)", y que evidencia a su vez, las patologías particulares de un determinado contexto histórico. Para Hörisch la literatura, como discurso social, es patognóstica ${ }^{2}$ ya que permite conocer no sólo la enfermedad de una época, sino a la enfermedad misma (gnoseología) y por ende cómo es percibida y descrita socialmente. La pregunta que se construye al entender a la literatura como saber patológico y gnoseológico, no es cuáles y cuántas son las enfermedades de una época, sino "porqué una determinada enfermedad se percibe públicamente (...) y se la tematiza en (...) la literatura (Hörisch, 2006, p. 56)". Retomamos a Hörisch para afirmar que la violencia del narcotráfico en los años ochenta y noventa enfermó a la sociedad colombiana y transformó el modo en que el país se narraba a sí mismo. Comprender al narcotráfico y sus manifestaciones violentas como una peste que contaminó (contamina) a Colombia, implica analizar sus significaciones, sus temas y sus figuras en las cuatro novelas seleccionadas La virgen de los sicarios (Vallejo, 1994), Comandante Paraiso (Álvarez Gardeazábal, 2002), Delirio (Restrepo, 2004) y El ruido de las cosas al caer (Vásquez, 2012); teniendo como punto de partida la pregunta de Hörisch: ¿Cómo y por qué se tematiza y figurativiza la violencia del narcotráfico? ¿Por qué y cómo la violencia significa? La respuesta de los dos interrogantes implica exponer los orígenes y los síntomas del narcotráfico como enfermedad, es decir presentar una nosología ${ }^{3}$ de la peste, para indagar en los tropos y topos de la violencia del narcotráfico, entendido como condición y dispositivo de producción (Verón, 1996) de la literatura analizada en este artículo.

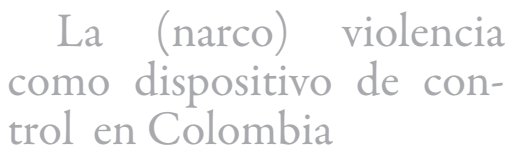

Alicia Vaggione (2013) en su libro Literatura/enfermedad considera la emergencia del sida como un acontecimiento discusivo que permite reflexionar sobre el presente histórico, entendiendo al acontecimiento como "aquello que surge de improvisto, que irrumpe insospechadamente, que trastoca la temporalidad dejando por un momento todo desajustado" (Vaggione, 2013, p. 29). Las palabras de Vaggione son el punto de partida de este apartado, ya que consideramos al narcotráfico como un acontecimiento histórico que irrumpió en los años setenta en la sociedad colombiana, desbarajustando el débil orden social y generando nuevas formas de relaciones entre los actores del conflicto armado; que se encargaron de instrumentalizar la violencia, haciéndola expresión del poder territorial y económico y, a la vez, un medio de negociación con el Gobierno colombiano. Si el narcotráfico como virus enfermó al país y como acontecimiento cambió la historia nacional; el interrogante que plantea este apartado es ¿Cómo se manifestó socialmente dicha peste? La respuesta apunta a la relación que se gesta entre violencia y narcotráfico, y a la implementación de la primera como dispositivo de

2, Para Hörisch el neologismo patognóstico fue acuñado por el psicoanalista y filósofo alemán Rudolf Heinz, para referirse a la relación que existe entre patología y gnoseología, ya que las enfermedades ofrecen "algo para detectar, por cierto las enfermedades son conocimiento (Hörisch, 2006, p. 53)".

3 La nosología como ciencia describe y explica el origen y síntomas de una enfermedad determinada. 
control social (Foucault, 2011); es decir la justificación del abuso de la violencia contra y entre los narcotraficantes, guerrilleros y paramilitares que posibilitó una apropiación colectiva de diversas modalidades violentas como instrumento coercitivo. ${ }^{3}$ Foucault (2011) en Los Anormales retoma la diferencia entre los dispositivos disciplinarios y los de seguridad como modelos occidentales frente a la enfermedad vista desde lo social. Los primeros, bajo los preceptos de la disciplina que marcan la diferencia entre lo normal y lo anormal, anulan el contagio a partir de la exclusión; por ejemplo, el tratamiento y trato dado a los leprosos, expulsados de la comunidad y por ende marginados jurídica y políticamente. Por otra parte, los dispositivos de seguridad controlan la circulación de la enfermedad a partir de la inclusión del infectado, lo que Foucault ejemplifica a partir de las ciudades en cuarentena a causa de la peste, y que tienden al sometimiento y control del cuerpo. En el caso colombiano, es el cuerpo social el que se ve sometido al control de la violen- cia, que organiza las nuevas relaciones de poder, gestadas con la irrupción del tráfico de drogas.

$\mathrm{Si}$ el narcotráfico puede ser considerado como un virus que infecta a Colombia, cuyo factor de contagio se simboliza en el dinero fácil y rápido, la violencia sería el dispositivo de seguridad que normativizará las relaciones; lo que permite afirmar que "las interacciones cotidianas están sometidas a rituales fundados sobre la violencia (Pécaut, 2001, p. 124)”. El miedo es entonces el mediador de las relaciones sociales, los narcos, los pobres, los jóvenes sicarios, la Policía ${ }^{4}$, los paramilitares y guerrilleros enuncian en sus acciones la amenaza frente al otro, construyendo el estado patológico en el que se manifiesta la narco-violencia, y entendiendo al estado (Foucault, 2011) como la base anormal que permite el desarrollo de dicha enfermedad.

Vivir con miedo, significa aniquilar la posibilidad de un futuro y sujeta al hombre a un presente de incertidumbre, en el que el otro siempre representa la arbitrariedad de la violencia (Sofsky, 2006). El miedo, como una de las significaciones que adquiere la narco-violencia, teje las relaciones sociales, y por ende, marca la vida de los colombianos que "sobreviven". La sospecha tejida bajo la gestión social del miedo, reconstruye la narración de Antonio Yammara en El ruido de las cosas al caer, testigo y sobreviviente de la violencia del narcotráfico, al sentir que su vida está regida por el terror. El héroe de la novela percibe que el miedo regula su relación con el mundo y que los efectos de dicha dialéctica, literalmente, lo enferman:

Las noches. Recuerdo las no-
ches. El miedo a la oscuridad
comenzó en esos últimos
días de mi hospitalización,
y sólo desaparecería un año
después: a las seis y media de
la tarde, la hora en la que cae
la noche súbita en Bogotá, el
corazón me empezaba a latir
con furia, y al principio se re-
quirió el esfuerzo dialéctico
de varios médicos para con-

3 Rosana Reguillo, al referirse a la violencia del narcotráfico como dispositivo de control social en las ciudades mexicanas fronterizas, afirma: "Ni Foucault imaginó un dispositivo de vigilancia y control, más sofisticado y eficiente. El mensaje es claro, sálvese quien pueda (Reguillo, 1998, p. 28)."

4 Walter Benjamin (2001) en Para una critica de la violencia afirma que la policía es la manifestación de las dos clases de violencia del Derecho, ya que por una parte justifica a la violencia como medio de la justicia (Derecho natural); y por otra parte garantiza la Justicia de los fines al legalizar a la violencia (Derecho positivo). Para Benjamin la Policía en la democracia es la máxima degeneración de la violencia de lo cotidiano, ya que evidencia su carácter mediador y su cotidianidad refleja la fundación y sostenibilidad del poder en la violencia misma. 
vencerme de que no estaba a punto de morir de un infarto (Vásquez, 2011, p. 56).

La narco-violencia que azotó(a) al país y que se expresó a partir de magnicidios, ataques terroristas, asesinatos, exterminios políticos, masacres y secuestros, resignificó el sentido de la existencia humana y por ende de la muerte; cuestionó la ética nacional alrededor del poder del dinero; cambió la percepción del espacio público instaurando nuevas dinámicas que encerraron en/a las ciudades a la población civil, generando otras configuraciones cognitivas sobre la experiencia urbana, en la que el temor compartido, era el gran gestor social. La ciudad, como lugar geográfico del narcotráfico, es entonces el nuevo espacio de la muerte violenta, como máxima expresión social de lo narco, el escenario en el que se gesta y cobra sentido la falta de horas sin muertos; “(...) el lugar donde la muerte violenta se produce (...) se codifica: demarca territorios y se ritualiza (...) se significa, esto es, se dota de sentido y de significación (Blair, 2004, p.85)". Aunque sea la novela de Vallejo, la que mejor da cuenta de esa ausencia de vivos, en los cuatro textos, la ciudad es representada como un espacio en el que la violencia deja huellas; no sólo en las ruinas generadas por los atentados terroristas o por los barrios que simbolizan la desigualdad social; los cuerpos de los sicarios y el oropel de la casa de los narcotraficantes son, a su vez, huellas que recrean la narco-violencia urbana. Es desde los cuerpos/ cadáveres de los sicarios que Medellín, Medallo/Metrallo, es representada como un intersticio espacial en el que la muerte violenta (se) naturaliza.

Alejandro Gaviria (2010) en su artículo "Cambio social en Colombia durante la segunda mitad del siglo XX" señala que en 1991 la tasa nacional de homicidios era de 380 muertos por cada 100.000 habitantes y el asesinato era la principal causa de muerte en el país. Gaviria señala como factor determinante de esta "epidemia homicida" al narcotráfico, concentrando en Bogotá, Cali y Medellín el $50 \%$ de las tasas de homicidio a nivel nacional y haciendo de la narco-violencia un asunto de salud pública que modificó a la familia colombiana, puso en peligro a los hombres jóvenes y aumentó la brecha poblacional entre los dos sexos.

Consecuencia inmediata de esa epidemia fue la indiferencia frente al hiperbolismo de la narco-violencia. Si Colombia es el país de la desmesura artística, ya sea desde la obesidad figurativizada en los cuadros de Botero, o en el tono hiperbólico de los textos de García Márquez (Blair, 2004); su violencia también es excesiva, y al ser excepcional; pareciese que fuera tan real como la desproporción de los cuerpos del pintor colombiano, o como las mariposas amarillas que llegaban con los pasos de Mauricio Babilonia. Lo que afirma Blair (2004) en Muertes violentas. La teatralización del exceso es que el desmán de muertos cuestionó la realidad y la respuesta por parte de la sociedad fue denegar; es decir, naturalizar los hechos (las tasas de homicidio, la aparición de sicariato, los magnicidios, las bombas, las masacres, etc.) e invisibilizar a la violencia.

El exceso de cadáveres, los cuerpos como narradores de la deshumanización, el olvido y la abulia crearon una topografía de la muerte (Blair, 2004) en Colombia y la posibilidad de interpretar al país desde esta manifestación de violencia, transformando la relación entre los vivos y los muertos. Se configuró un espacio simbólico que evoca a Comala y en el que se empezó a gestar una taxonomía que describió lo que quedaba de una vida (Giorgi, 2012)5: exiliados, desaparecidos, muertos anónimos, bajas de los actores del conflicto armado, sicarios, muertos políticos y testigos inocentes; voces reconstruidas desde los textos seleccionados, que permiten comprender las significaciones del fenómeno social de la narco-violencia en la sociedad colombiana. 
Las principales ciudades se transformaron en el espacio simbólico del desarraigo, de la pobreza y la exclusión social. Bogotá será el escenario de los magnicidios, de los muertos políticos y de las bombas, el símbolo de una ciudad sitiada por el terror de la violencia del narcotráfico y de la que dan cuenta los textos de Restrepo y de Vásquez que, como escritores capitalinos, centran la tensión en la imposibilidad de prever el inicio y el fin de los ataques terroristas; es decir, en la construcción narrativa del valor fantasmagórico que adquirió la violencia como dispositivo de control. Cali y Medellín narradas en Comandante Paraíso y La virgen de los sicarios, respectivamente, se encargan de enterrar sicarios y condenar inocentes al anonimato; mientras en el campo colombiano, geografía del Conflicto, desaparecen cuer- pos, caen guerrilleros, paramilitares y soldados. Lo que permite el reconocimiento de las huellas de producción de sentido (Verón, 1996) en las novelas (tropos y topos de la violencia del narcotráfico), entendiendo al narcotráfico como dispositivo de producción, es que a mediados de los años ochenta Colombia se reconoce socialmente como un país enfermo y controlado por la muerte violenta, una sociedad contagiada por un virus autoinmune ${ }^{6}$, que se sustenta en la ausencia de Estado y en el abandono de la legalidad democrática. La pregunta que atraviesa la construcción narrativa de la narco-violencia en las cuatro novelas, es por qué y cómo la violencia significa, y las respuestas se gestan en la representación de un país carente de Estado y con una democracia pobre $^{7}$ que sustenta la desigualdad.
La guerra contra el Estado, liderada por Pablo Escobar, extendida hasta 1993, manifiesta la función de la narco-violencia como dispositivo de control social, haciendo de El Patrón el ícono de dicho dispositivo; es a la vez un síntoma claro de la permisividad gubernamental, al dejar que la violencia fuese el medio para negociar la extradición. El 19 de junio de 1991 El Patrón decide entregarse a las autoridades colombianas, para ser encerrado en una cárcel diseñada por y para él, después de esperar que la Asamblea Constituyente, no aprobara el Tratado de Extradición con Estados Unidos. La Catedral, prisión en la que Escobar siguió delinquiendo y de la que se escapará un año después, puede ser leída como símbolo de la laxitud de la Justicia colombiana, una burla al sistema penitenciario nacional y

5 Gabriel Giorgi, en su artículo "Lo que queda de una vida. Cadáver, anomia y comunidad", indaga a partir de las obras de Teresa Margolles, Roberto Bolaño y Néstor Perlhongher, la recreación de la muerte violenta en el norte de México, afirmando que los tres artistas combaten simbólicamente a la tanatopolítica (Agamben), al recuperar en la memoria los cadáveres (anulación de la persona) que ha dejado la narco-violencia en esta zona fronteriza. Ver: Giorgi, Gabriel (2012) "Lo que queda de una vida. Cadáver, anomia y comunidad" en Revista Diecisiete. Teoría critica, psicoanálisis, pensamiento, México, D.F., Instituto de Estudios Críticos.

6 Derrida, en una entrevista concedida a Giovanna Borradori (2003), frente al horror del 11 de septiembre de 2001, señala que, tanto el desarrollo y el fin de la Guerra Fría, como el nuevo "equilibrio del terror" de esta era entregada al miedo, actúan a partir de un proceso autoinmune, al atacar sus propias defensas contra la violencia; es decir, "ese extraño comportamiento del ser vivo que, de manera casi suicida, se aplica a destruir «él mismo» sus propias protecciones, a inmunizarse contra su «propia» inmunidad (Borradori, 2003 , p. 243)". En el caso de los años ochenta y noventa en Colombia, el paso de una inicial permisividad del Estado -interpretada como ausencia- frente a la relación benéfica del narcotráfico con las instituciones sociales y políticas, a un ataque contra el tráfico de drogas y de dichas relaciones, puede ser leído como un acto autodestructivo que erosiona a la sociedad civil.

7 Ansaldi (2011) define a la democracia latinoamericana como pobre en lo económico y social, y de pobres en lo político, lo que ha perpetuado el estado de desigualdad en América Latina. 
un triunfo de la violencia como instrumento mediador. Es desde el poder simbólico de ilegalidad que representó La Catedral, que Fernando Vallejo, dándole voz a su avatar autobiográfico, describe cómo la prisión con nombre de templo católico se convirtió en el refugio del narcotráfico, confirmando el imaginario social de divinidad construido alrededor de El Capo:

Al Sumo Pontífice o capo de los capos o gran capo, para protegerlo de sus enemigos, los otros capos, esta ocurrencia que tenemos de presidente le construyó una fortaleza con almenas llamada La Catedral, y pagó para que lo cuidaran, con dinero público (o sea tuyo y mío, que lo sudamos), un batallón de guardias del pueblo de Envigado que el gran capo escogió: "Quiero a éste, a aquél otro. A ese de más allá no lo quiero porque no le tengo confianza" (Vallejo, 1994, p. 60-61).

Con la muerte de Pablo Escobar no terminaron las crónicas del perico, ${ }^{8}$ ni disminuyeron las modalidades de violencia del conflicto armado. Lo que sucede a partir de 1993 es que la narco-violencia se expresó y reconoció a partir de asesinatos selectivos, ataques e inyección de fondos, por parte de los carteles, ${ }^{9}$ a la guerrilla y paramilitares. Analizar en el corpus seleccionado la construcción narrativa de los fenómenos de la narco-violencia, magnicidios y terrorismo, entendidos como síntomas de los años de la peste, es el objetivo del siguiente apartado; confirmando, por un lado, que la violencia al convertirse en un dispositivo de control se profesionalizó; y por otra parte, que el dinero se convirtió en el vector de transmisión, contaminando todas las instituciones nacionales y naturalizando en la cotidianidad el discurso bélico, que polariza a la sociedad colombiana hasta el día de hoy.

Síntomas de la peste: la construcción narrativa de la narco-violencia

Los magnicidios: Colombia, la democracia más valiente del mundo ${ }^{10}$

El 11 de marzo de 1984, la Policía Nacional, apoyada por la DEA, allanó y destruyó Tranquilandia, el complejo de pro- ducción de cocaína más grande de América Latina hallado hasta el momento. Un mes más tarde, el 30 de abril de 1984, el entonces ministro de Justicia Rodrigo Lara Bonilla es asesinado en Bogotá por dos menores de edad; hace 30 años el país supo, por primera vez, qué es un sicario y se reconoció públicamente el poder pulverizador de la violencia del narcotráfico. El primer asesinato de un ministro de Justicia en la historia de Colombia señala simbólicamente el inicio de la devastadora guerra del narcotráfico contra el Estado colombiano, que se extenderá hasta finales de los años noventa y que tendrá como acción constante el magnicidio (uno al año en promedio), sobre todo de líderes políticos, que representaban un peligro para los narcotraficantes.

Los asesinatos selectivos, según Blair (2004), han sido una práctica de la violencia en Colombia que se incrementó con la irrupción del narcotráfico y que tuvo en los años de la peste el objetivo de defender los intereses de los narcotraficantes: establecer una relación "legal" y por ende socialmente aceptada

8 Palabra que se usa en Colombia para nombrar a la cocaína. La expresión “crónicas del perico” es usada por Gustavo Álvarez Gardeazábal (2002) para referirse a la historia del narcotráfico en este país.

9 La palabra cartel, con su connotación de poder socioeconómico, es usada por primera vez en Alemania a finales del siglo XIX para referirse a una actividad económica monopolista. El término es retomado por Estados Unidos en la década de los ochenta, para indicar de modo exclusivo, a los grupos de colombianos que exportaban coca a ese país.

10 Este fue el título de un artículo publicado en abril de 1990 por el diario español El País en el que se analizaba la situación generada en la democracia colombiana a partir del asesinato de tres candidatos presidenciales en menos de nueve meses. 
entre el narcotráfico y el ejercicio político; anular del Tratado de Extradición; y eliminar los partidos de izquierda, en los que veían no sólo la representación política de la guerrilla, sino una muestra de debilidad por parte del Estado, al darles cabida en la vida democrática del país. En la contienda electoral por la Presidencia que se desarrolló entre 1989 y 1990, tres de los doce candidatos fueron asesinados. La muerte de Luis Carlos Galán, Bernardo Jaramillo Ossa y Carlos Pizarro pueden ser leídas como símbolos de la relación que se estableció entre muerte violenta y ejercicio político; es decir, representar una amenaza para los intereses del narcotráfico, significaba, en cierta medida, una condena a muerte. Los magnicidios desbordaron los límites del ejercicio democrático y generaron una transformación en el sentido de los lugares comunes, configurando una nueva apropiación del espacio público; por ejemplo, los velorios de los candidatos presidenciales en el Capitolio Nacional fueron interpretados como una forma de movilización social, frente a la incapacidad del Estado de garantizar el derecho a la vida.

Los desplazamientos interpretativos sobre los lugares públicos y en cierta medida, sobre el territorio nacional (entendido como un espacio habitado por muertos) son operaciones y construcciones de sentido propias de la narco-violencia, de las que da cuenta el corpus. Los límites modernos establecidos a partir de la relación dicotómica entre civilización y barbarie, normal y anormal, entre otros, se desdibujan en los intersticios (espaciales, interpretativos y epistemológicos) que produce la emergencia narco, reconstruidos en las cuatro novelas, que narran desde diferentes perspectivas (sociales), la capacidad de la sociedad colombiana de convivir con la muerte violenta.

Tanto en La virgen de los sicarios como en Comandante Paraíso, el uso de una gramática antinacional (Ludmer, 2010) expresa el sentimiento de rechazo a las instituciones colombianas. En la primera, y acorde al tono de diatriba ${ }^{11}$ que caracteriza a Vallejo, el narrador adjudica al olvido, una endemia nacional que a su vez posibilita la ilegalidad, la capacidad de sobrellevar la muerte al estado de amnesia y anomia que describe a la sociedad narcotizada:

La fugacidad de la vida humana a mí no me inquiera; me inquieta la fugacidad de la muerte: esa prisa que tienen aquí para olvidar. El muerto más importante lo borra el siguiente partido de fútbol. Así, de partido en partido se está liquidando la memoria de cierto candidato a la presidencia, liberal, muy importante, que hubo aquí y que tumbaron a bala de una tarima unos sicarios, al anochecer, bajo las luces dramáticas y ante veinte mil copartidarios suyos en manifestación con banderas rojas (Vallejo, 1994, p. 40).

Por su parte, Gardeazábal en Comandante Paraiso, al darle voz a los narcotraficantes en las narraciones de Londoño y Gabriel, describe la utilidad de la muerte de Galán en la lucha de los extraditables contra el Gobierno, en aras de garantizar en primer lugar, sus relaciones con las instituciones políticas

\footnotetext{
11 La diatriba para Josefina Ludmer (2010) en Aqui América latina. Una especulación es instrumento narrativo correspondiente a un tono antinacional, característico de algunos textos latinoamericanos de la década de los noventa. Corresponde narrativamente al intencional ataque - Ludmer lo define como profanación -, a los bienes nacionales supremos: la Iglesia y el Estado; y caracteriza lo que la autora define como el género narrativo antinacional latinoamericano, necesario en los procesos de descolonización de la última década del siglo XX. Es la diatriba, el cinismo, el performance verbal lo que diferencia al texto de Vallejo en el corpus seleccionado.
} 
del país; y en consecuencia, la no firma del Tratado de Extradición. Enrique Londoño, avatar de Pablo Escobar, afirma que Galán, "ha sido el mejor muerto que ha tenido este país" (Álvarez Gardeazábal, 2002, p. 175).

Los dos textos atacan a los bienes nacionales supremos, Iglesia y Estado, y a su vez narran cómo el narcotráfico en los años noventa se institucionalizó en el país. La voz antipatriótica (la necesidad del olvido y la utilidad de la muerte de un político) se dirige también al nuevo bien nacional y a su ejercicio de paralegalidad (Reguillo, 2010), descrito a partir del uso de la violencia; lo que sustenta el tono de diatriba reflejado en el cuestionamiento a la identidad nacional. El ataque a la institución del narcotráfico confirma que Colombia es un país contaminado por un virus autoinmune que se destruye a sí mismo; Vallejo lo enuncia desde la apropiación del parlache y Gardeazábal lo hace desde el tono performativo de la narración de Londoño, pero los dos textos representan la tolerancia frente a la muerte violenta como expresión social del tráfico de drogas.

La desolación y orfandad política son otras de las significaciones de la narcoviolencia que construyen los relatos de los personajes/ héroes de El ruido de las cosas al caer y de Delirio. Yammara, el protagonista de la novela de Vásquez, reconoce que los magnicidios marcaron su existencia, tejiendo su historia personal; y que como bogotano que creció en los años ochenta, puede reconstruir eso que se llama "vida" a partir del (sin) sentido histórico generado por los magnicidios y en el que se reconoce una generación completa de colombianos:

(...) Yo tenía catorce años, esa tarde 1984 en que Pablo Escobar mató o mandó a matar a su perseguidor más ilustre, el ministro de Justicia Rodrigo Lara Bonilla (dos sicarios en moto, una curva en de la calle 127). Tenía dieciséis años cuando Escobar mató o mandó a matar a Guillermo Cano, director del El Espectador (a pocos metros de las instalaciones del periódico, el asesino le metió ocho tiros en el pecho). Tenía diecinueve años y ya era un adulto, aunque no había votado todavía, cuando murió Luis Carlos Galán, candidato a la presidencia del país, cuyo asesinato fue distinto o es distinto en nuestro imaginario porque se vio en televisión: la manifestación que vitoreaba a Galán, luego las ráfagas de la metralla, luego el cuerpo desplomándose sobre la tarima de madera, cayendo sin ruido o su ruido oculto en el bullicio del tumulto y por los primeros gritos (Vásquez, 2012, p. 1819).

En Delirio, la representación de una Colombia como cuerpo social huérfano, sin futuro y sin memoria, se construye a partir de la descripción de la enfermedad mental de Agustina, personaje que simboliza el estado de locura de la sociedad colombiana en los años de la peste. Uno de los narradores del delirio es Aguilar, que comprende que la principal causa de la falta de razón de su mujer es la ausencia de recuerdos y la posterior construcción de un futuro sin pasado; "es que el delirio carece de memoria, que se reproduce por partenogénesis, se entorcha en sí mismo y prescinde del afecto, pero sobre todo que carece de memoria" (Restrepo, 2004, p. 75).

Las vidas que cobran sentido, que significan y se reconocen a partir de los magnicidios y la imposibilidad de reconstruir la vida nacional son algunos de los temas que construyen la violencia en las novelas de los dos autores bogotanos, Restrepo y Vásquez; una narración desde la intimidad que se contrapone a la gramática antipatriótica de Vallejo y Álvarez Gardeazábal. La oposición de las dos construcciones narrativas sobre los magnicidios, particularmente el de Galán, se fundamenta por una parte en las posturas que 
tienen los escritores en la literatura nacional. Vallejo y Álvarez Gardeazábal enuncian un discurso distópico que rompe la hegemonía cultural fundamentada en la heterosexualidad $y$ en el centralismo nacional condensado en Bogotá; por su parte, Restrepo y Vásquez, con sus textos construyen una visión esperanzadora sobre la función social de la literatura, como solución poética a la violencia.

Hoy, el monumento a Lara Bonilla, la tumba de Galán o de Pizarro rememoran el impacto político del narcotráfico y su capacidad de doblegar al sistema judicial, al lograrse la no aprobación del Tratado de Extradición en la Constitución de 1991. ${ }^{12}$ Si la tumba de Pablo Escobar puede ser considerada el templo del Colombian dream, el monumento a Lara y las tumbas de los candidatos presidenciales condensan los alcances de la narco-violencia; pero la relación entre todas las muertes evidencia, que como epidemia histórica (Foucault, 2011), el narcotráfico contaminó violentamente al país.

El narcoterrorismo: edificios, cuerpos y zapatos los nuevos adornos del cielo

Hannah Arendt (2006) afirma que lo ocurrido en los cam- pos de concentración alemanes, más que un genocidio, significa el asesinato administrativo en masa bajo el funcionamiento de una maquinaria totalitaria que tenía como objetivo la dominación del mundo. El aniquilamiento de la condición humana bajo el abuso de la violencia como instrumento, que tuvo como símbolo la implementación de los campos de exterminio para la eliminación burocrática de toda una raza, tiene como máxima la cancelación histórica de las víctimas, la negación de su condición y por ende de su paso por el mundo. En Sobre la Violencia (2006), Arendt pone como opuesto del poder político (colectivo y público) a la violencia (instrumental) que, implementada como medio en la ausencia de poder, lo sustituye, generando el terror que deshumaniza, silencia al hombre, alejándolo de su capacidad de comunicar. El terror, entendido como la forma de Gobierno que se establece cuando la violencia ejerce total control, genera una crisis de sentido en la que ya no existen los motivos humanos (el lenguaje) y en la que la pregunta sobre qué es un hombre se deshace en la reproducción (técnica) de cuerpos para el sacrificio. Los cadáveres anónimos de los campos de concentración, la indiferencia de los nazis al caminar por las ruinas adornadas por la ausencia de vida, los muertos a quien nadie llora, porque su identidad fue aniquilada, transformaron al mundo occidental y evidenciaron la dificultad de abordar, interpretar y analizar dicha perversidad.

Rosana Reguillo (2011) establece similitudes entre la actual narco-violencia en México y la crisis humanitaria generada por la guerra contra las drogas, y la violencia que caracterizó al nazismo; ya que las dos comparten el establecimiento del terror como forma de Gobierno, la disolución de la persona (identidad), el cuerpo/cadáver leído como un índice degenerado (Reguillo, 2011), ${ }^{13}$ la unidireccionalidad de la violencia misma que aparece como una presencia fantasmagórica, en la que es imposible determinar el inicio y el fin, y cuyo patrón de conducta es incompresible. Lo anterior confirma que el narcotráfico, al igual que el nazismo, instrumentaliza a la violencia como dispositivo de control, sometiendo a la población al terror como forma de gobierno.

La presencia de la narco-violencia en la sociedad colombiana trascendió a la muerte y procuró borrar el rastro de las víctimas con la proliferación de masacres y bombas, modalidades de violencia que reflejaron la profesionalización de la violen-

12 El Tratado de Extradición a EEUU se aprobó en 1997 por el Senado de la República. A partir del mandato del Presidente Pastrana (1998-2002) ha sido usado como herramienta legal de la lucha contra el narcotráfico. 
cia misma. En la noche del 18 de agosto de 1989, después de confirmarse la muerte de Luis Carlos Galán, el Presidente Virgilio Barco declara el estado de sitio; la respuesta de la narcomáquina fue el terror, dando inicio a lo que históricamente ha sido llamado la ofensiva narcoterrorista. ${ }^{14}$ En este apartado profundizamos en la reconstrucción narrativa de la implementación de las bombas como modalidad de violencia que usaron los narcotraficantes bajo el liderazgo de Pablo Escobar; confirmando lo que afirma Arendt, que "(...) la extrema forma de violencia es la de uno contra todos" (Arendt, 2006, p. 57). ${ }^{15}$

El narcoterrorismo es construido narrativamente en dos textos del corpus, Delirio y El ruido de las cosas al caer, de modo específico en la novela de Vásquez que, con el título como designador narrativo, plantea desde el inicio la interpretación sobre un país que se acostumbró al sonido de las cosas que caían: aviones, cenizas, personas, objetos, edificios, zapatos; es decir, al ruido de la muerte. Los atentados perpetrados contra las instalaciones del DAS (policía secreta colombiana), los periódicos El Espectador y Vanguardia Liberal, la Plaza de Toros de la Macarena, el Centro Comercial 93 y el avión de Avianca HK-1803, entre otros, pueden ser leídos como escenificaciones (Reguillo, 2010) del narcotráfico; es decir actos de violencia expresiva, que no sólo enuncian el poder del narcotráfico, sino su capacidad de controlar y disciplinar a la población a partir del terror. Los síntomas del terror se manifestaban en la paranoia permanente y expectante de un siguiente ataque que no se podía prever, el miedo como controlador de las relaciones sociales gestó un estado de conmoción interior ${ }^{16}$ que endurecía la lucha antiterrorista, y simultáneamen- te a la violencia expresiva. El delirio de Agustina (Restrepo, 2004), como metáfora de la locura nacional provocada por la emergencia de lo narco, se intensifica con el ruido de las bombas; el temor de Aguilar frente a un posible estado de conmoción emocional de su esposa, significa la imposibilidad de comprender las consecuencias mentales de los actos terroristas en la locura de su mujer; es decir, la dificultad de comprender los nuevos sentidos que adquiría la violencia como instrumento de poder paralegal.

Lo que caracteriza la construcción narrativa del narcoterrorismo en el texto de Vásquez es la oposición entre la resignación de saberse vivo y el estallido de la muerte. El momento en que Ricardo Laverde, acompañado por Antonio, va a la Casa de Poesía Silva para escuchar la grabación de la caja negra del avión en el que murió su esposa,

13 Rosana Reguillo (2011) analiza los efectos de la narcomáquina en el México actual y en la crisis humanitaria desencadenada a partir de la guerra contra el narcotráfico declarada en el Gobierno de Felipe Calderón. A partir de un estudio del cuerpo como discurso en la narcoviolencia, Reguillo, retomando a Adriana Caravero, afirma que los cuerpos desarticulados, rotos y masacrados que parecen "brotar" en el norte mexicano, son un residuo de escenas de tortura a las que es imposible acceder, por lo que operan como índices degenerados; ya que su segundidad, retomando a Pierce, es a la violencia del narcotráfico, entendida como referencia (abstracta) y no como referente (concreto).

14 Sobre los secuestros llevados a cabo por Pablo Escobar, Gabriel García Márquez escribió Noticia de un secuestro, publicada en 1996. Independientemente de la calidad literaria de la crónica o de la posición política del escritor, es relevante que el Nobel colombiano haya decidido escribir sobre este capítulo de la historia nacional, haciendo de Pablo Escobar un personaje en la novela. Los secuestrados fueron: Maruja Pachón, Alberto Villamizar, Beatriz Villamizar de Guerrero, Marina Montoya, Francisco Santos, Diana Turbay, Richard Becerra, Orlando Acevedo, Hero Buss.

15 Henderson (2012) afirma que la ofensiva narcoterrorista en Colombia no tiene símiles ni precedentes en la historia de los Estados modernos democráticos; y aunque se diga que la situación actual mexicana es similar a lo vivido en esa época en el país, en México no ha implicado un ataque a las instituciones democráticas, ni exterminio político, ni violencia directa e indiscriminada que somete a la población civil. 
puede ser interpretado como el detonante narrativo para recrear la historia de la violencia del narcotráfico a partir de la reconstrucción de la vida de Laverde, metonimia de esa sombra larga y fantasmagórica en la que se transformó la violencia en la sociedad colombiana, donde las motos eran el vehículo de la muerte, "Los hombros de Ricardo Laverde comenzaron a sacudirse; (...) Pensé Y era una sola sombra larga, absurdamente el verso volvió a la cabeza; y en ese mismo instante vi una moto que había estado quieta hasta ahora en la acera" (Vásquez, 2012, pp. 48-50).

Los textos de los dos escritores bogotanos reconstruyen cómo la incursión narcoterrorista tuvo como objetivo primordial la capital, al estar centralizadas todas las instituciones del Estado en Bogotá; a su vez que la violencia expresada a partir de bombas, anulaba la dinámica selectiva de los asesinatos, y exponía a toda la sociedad civil a una condición de víctima en una guerra declarada entre los carteles del narcotráfico y el Gobierno colombiano. Tanto Restrepo como Vásquez representan, desde las historias de vida de sus personajes, al narcoterrorismo como un fenómeno que desarticuló al país, enloqueciéndolo (como a Agustina) o haciéndolo disfuncional (como Antonio Yammara). Las dos novelas figurativizan este síntoma de los años de la peste desde los efectos de la violencia en la cotidianidad; por ejemplo, a partir de la imposibilidad de definir qué significa ser persona en medio del terror; del disvalor de la vida humana; y de los anticuerpos generados, como la locura y la disfunción eréctil, agentes de esta enfermedad autoinmune que destruye al país.

Es importante señalar que la ausencia de recreación de la oleada narcoterrorista en $L a$ virgen de los sicarios se justifica en que el propósito de Vallejo es narrar el impacto de la muerte de Pablo Escobar en la cotidianidad colombiana simbolizada en los sicarios, que sin patrón se dedicaron a la prostitución. Por su parte, Gustavo Álvarez Gardeazábal, aunque construya al personaje de Londoño a partir de la figura de Pablo Escobar, la narración de la violencia del narcotráfico en Comandante Paraíso se enuncia desde la historia del Cartel de Cali, que no fue responsable directo del narcoterrorismo y que optó por negociar legalmente con el Gobierno.
El Estado finalmente cedió y el 19 de junio de 1991 fue aprobado el Art.35 de la Constitución en el que se prohibía la extradición; al día siguiente Pablo Escobar se entrega, dando fin a la ofensiva terrorista con una declaración en la que admitía haber ayudado solamente a traficar 400 kilos de coca a Europa y Medio Oriente y nunca declaró su responsabilidad frente a un Juez de ninguno de los actos terroristas que se le han adjudicado. Son los efectos de esta yuxtaposición entre paralegalidad y legalidad, entendidos como manifestaciones de violencia, los que construyen la tensión narrativa de las cuatro novelas y que hacen sentido en las palabras del Midas (Restrepo, 2004) : "Voy a invertir mi fortuna en hacer llorar a esta país, así me había dicho Pablo, Agustina bonita, y su fortuna debe ser la más grande del mundo, y si por cada dólar el hombre consigue arrancarnos una lágrima, calcula cuánto nos falta por llorar (Restrepo, 2004, p. 211)." El corpus describe ese espacio social paralelo que se construyó con la emergencia del narcotráfico que, con códigos y reglas propios, evidenció los quiebres (ausencia) del Estado colombiano, haciendo llorar a la población civil.

16 En la Constitución de Colombia, el Art.231 expone que el estado de conmoción interior debe adoptarse cuando se presenta una grave perturbación del orden público que atente contra las instituciones del Estado y la seguridad ciudadana. 


\section{Consideraciones finales}

Magnicidios y atentados terroristas son algunas de las modalidades de violencia con las que se expresa socialmente la narcomáquina. La ausencia de Estado, encargado de contener en la Fuerza Pública a la violencia, dotó de libertad a la violencia misma; Colombia en el corpus es construida como una Nación que democratiza a partir del espectáculo del terror que "ofrecen" los narcotraficantes. El derroche económico, el exceso de muertos, el desborde de la violencia, el delirio constante, la monstruosidad del poder encarnada en la figura de Pablo Escobar, un país enfermo que se describe a sí mismo como cuer- po social contagiado y espacio físico habitado por muertos (topografía de la muerte), son los síntomas recreados en las novelas que confirman la desmesura como significación del narcotráfico y reconstruyen la pluralidad de significados que ha adquirido la violencia en la sociedad colombiana. William Ospina (2002), retomando las últimas páginas de Los Funerales de la Mama Grande de Gabriel García Márquez, afirma que lo que le hace falta a Colombia para dejar de ser víctima de su cultura violenta, es que alguien se tome el trabajo de contar los dolores, para que la tragedia que azota al país desde mediados del siglo XX, no sea olvidada; por eso, la literatura nacional se ha encargado de "cantar", como lo hiciera Homero, la epopeya de los sobrevivientes de la guerra, para que el país sepa "cómo convertir en rapsodia su arte incomprensible de vivir siempre en peligro, la curiosa relación con la guerra y con la muerte que nos caracteriza" (Ospina, 2002, p. 2). Indagar en los tropos (y topos) que recrean los años de la peste significa poder comprender la violencia como significante que atraviesa a la sociedad colombiana, y entender cómo la literatura ha reconstruido los procesos sociales en un país que lleva sesenta años de conflicto, y que se sustenta, desde los años ochenta, ideológica y económicamente, en la dinámica violenta de la narcomáquina.

\section{Referencias}

Álvarez Gardeazábal, G. (2002). Comandante Paraíso. Bogotá: Mondadori.

Ansaldi, W. (2011). Democracia y apartheid en sociedades fragmentadas. En: Alcázar, J. (Ed). Historia actual de América Latina, 1959-2009 (pp.203-280).Valencia: Tirant Lo Blanch.

Arendt, H. (2007). El origen del totalitarismo. Madrid: Taurus.

Arendt, H. (2006). Sobre la violencia. Madrid: Alianza.

Benjamin, W. (2001). Para una critica de la violencia y otros ensayos. Bogotá: Taurus.

Blair, E. (2004). Muertes violentas. La teatralización del exceso. Medellín: Universidad de Antioquia.

Borradori, G. (2003). La filosofía en una época de terror. Madrid: Taurus,

Foucault, M. (2011). Los Anormales. México: Fondo de Cultura Económica.

Gaviria, A. (2010). Cambio social durante la segunda mitad del siglo XX. En Documentos CEDE. Bogotá: Universidad de los Andes. 
Giorgi, G. (2012). Lo que queda de una vida. Cadáver, anomia y comunidad. Revista Diecisiete. Teoría crítica, psicoanálisis, pensamiento: Recuperado 30 de septiembre de 2014 de http://www. slideshare.net/anormales-originales/lo-que-queda-de-una-vida-cadver-anonimia-comunidad.

Henderson, J. D (2012). Víctimas de la Globalización. La historia de cómo el narcotráfico destruyó la paz en Colombia. Bogotá: Siglo de Hombres Editores.

Hörisch, J. (2006). Las épocas y sus enfermedades. El saber patognóstico de la literatura. En: W. Bongers y T. Olbrich (comp.). Literatura, cultura, enfermedad (pp. 47-72). Buenos Aires: Paidós.

Ospina, W. (2002). Colombia en el planeta. Medellín: PNUD.

Pécaut, D. (2001). Guerra contra la sociedad civil. Bogotá: Espasa.

Reguillo, R. (1998). Imaginarios globales, miedos locales. La construcción social del miedo en la ciudad. Ponencia presentada en el IV Encuentro de la Asociación Latinoamericana de Investigadores de la Comunicación, ALAIC, Recife, Brasil, Universidad Católica de Pernambuco. Recuperado el 15 de septiembre de http://www.eca.usp.br/associa/alaic/Congreso1999/2gt/Rossana\%20 Reguillo.doc

Reguillo, R. (2011). La narcomáquina y el trabajo de la violencia: Apuntes para su decodificación. Emisférica, N.Y.: Hemisférica Institute. Recuperado el 15 de septiembre de http:// hemisphericinstitute.org/hemi/es/e-misferica-82/reguillo

Restrepo, L. (2004). Delirio. Bogotá: Alfaguara.

Sofsky, W. (2006). Tratado sobre la violencia. Madrid: Abada.

Vaggione, A (2013). Literatura/Enfermad. Córdoba: UNC - CEA.

Vallejo, F. (1994). La virgen de los sicarios. Bogotá: Alfaguara.

Vásquez, J. G. (2011). El ruido de las cosas al caer. Bogotá: Alfaguara.

Verón, E. (1996). La Semiosis Social. Barcelona: Gedisa. 